\title{
GESTÃO DEMOCRÁTICA NA REDE MUNICIPAL DE ENSINO DE UBERLÂNDIA (2001-2004): LIMITES E POSSIBILIDADES DA DEMOCRACIA NA ESCOLA PÚBLICA ${ }^{i}$
}

\author{
Vilma Aparecida de Souza \\ $\mathrm{UFU}^{\mathrm{ii}}$ \\ vilmasouza@pontal.ufu.br
}

\section{RESUMO:}

O presente trabalho é baseado na dissertação de mestrado que teve como objeto de investigação a experiência de implementação da gestão democrática que ocorreu na rede municipal de Uberlândia - MG por meio da implementação de diretrizes do Programa Escola Cidadã. Teve como objetivo refletir sobre as políticas educacionais implementadas para a consolidação da gestão democrática do ensino público e suas implicações no processo de democratização da educação. Pode-se verificar que o Programa Escola Cidadã da SME de Uberlândia-MG não foi capaz de efetivar de forma plena a gestão democrática, pois não conseguiu romper com as estruturas centralizadoras que perpassam a estrutura da escola, esta marcada por uma tradição autoritária presente no sistema público de ensino brasileiro, inserido numa sociedade patrimonialista e clientelista.

Palavras-chave: Democracia. Gestão Democrática da Educação. Política Educacional.

\section{DEMOCRATIC MANAGEMENT AT UBERLÂNDIA'S MUNICIPAL SCHOOLS (2001-2004): DEMOCRACY LIMITS AND POSSIBILITIES AT THE PUBLIC SCHOOL}

\begin{abstract}
:
This paper is based on a Master's dissertation that had as object of investigation the experience of implementation of the democratic management occurred in Uberlândia-MG city schools by means of the implementation of guidelines of the Citizen School Program (Programa Escola Cidadã). It had as objective to reflect on the educational policies implemented for the consolidation of the democratic management of the public teaching and its implications in the process of education democratization. It was verified that the Citizen School Program of SME of Uberlândia-MG was not able to totally implement the democratic management, as it couldn't discontinue the centralizing structures that are inserted in the school structure, this one manifested by an authoritarian tradition, present in the Brazilian teaching public system, which is inserted in a patrimony and client centered society.

Keywords: Democracy. Democratic management of the Education. Educational policy.
\end{abstract}

\section{Introdução}

No início de 2001 a Rede Municipal de Ensino de Uberlândia-MG (RME/UDI) vivenciou um processo de implementação de ações em nome da gestão democrática. Esse processo teve como marco inicial a substituição de diretores escolares nomeados por diretores eleitos por meio de uma lista tríplice escolhida pelos profissionais da escola. 
A introdução do debate democrático favoreceu a mobilização dos educadores, ampliando-se, dessa forma, o espaço de discussão em torno da necessidade de democratização da escola. Esse debate em torno de uma escola democrática e cidadã teve como referência a Proposta Escola Cidadãiii de Porto Alegre-RS, suscitando um grande número de expectativas nos sujeitos envolvidos.

A Secretaria Municipal de Educação (SME), sustentada pelo discurso em prol da democracia e da construção de uma "Escola Cidadã", orientou ações num processo de reestruturação, organizado por várias iniciativas, tais como: a elaboração do Projeto Político Pedagógico das escolas, tendo como marco inicial um Seminário ${ }^{\text {iv }}$ realizado em setembro de 2001; a realização da eleição direta para diretor e vice-diretor ${ }^{v}$ no final do ano de 2001; e a consolidação da Carta de Princípios Político-Pedagógicos das Escolas da Rede Pública Municipal de Ensino de Uberlândia discutida e aprovada no I e II Congresso Constituinte Escolar que aconteceram nos anos de 2003 e 2004, respectivamente; a atualização da Proposta Curricular; e a organização do $1^{\circ}$ Fórum Municipal de Educação no ano de 2004, com o objetivo de fomentar a elaboração do Plano Municipal de Educação.

Diante dessas considerações, o presente artigo tem como objetivo geral refletir sobre as políticas educacionais implementadas no município de Uberlândia-MG no período de 2001 a 2004 para a consolidação da gestão democrática do ensino público e os limites e possibilidades no processo de democratização da educação.

Quanto aos procedimentos metodológicos, primeiramente foi feita uma pesquisa bibliográfica, com a finalidade de realizar o aprofundamento do referencial teórico que embasou a pesquisa e as posteriores análises dos dados levantados.

Em um segundo momento realizou-se uma pesquisa documental com o intuito de buscar nos documentos oficiais da Secretaria Municipal de Educação e dos arquivos escolares informações sobre o processo de implantação da gestão democrática na RME/UDI.

Em seguida, realizou-se uma pesquisa de campo por meio de entrevistas semiestruturadas aplicadas a uma amostra dos sujeitos envolvidos na proposta de implementação da gestão democrática na RME/UDI (gestores da SME e da escola, docentes e funcionários), no período de 2001 a 2004. O universo da pesquisa compreende uma amostra de oito escolas da RME/UDI, envolvendo trinta e dois atores que nelas atuam de forma direta e indireta. Para a seleção das escolas que fizeram parte da amostragem, foram considerados os seguintes aspectos:

a) realização de eleição direta para diretor e vice-diretor nos anos de 2001 e 2003;

b) participação no Congresso Constituinte Escolar, realizado em 2004 pela Secretaria Municipal de Educação, para a consolidação da Carta de Princípios PolíticoPedagógicos das Escolas Municipais da Rede Pública Municipal de Ensino de Uberlândia;

c) elaboração, parcial ou total, do Projeto Político Pedagógico a partir da Carta de Princípios Político-Pedagógicos das Escolas Municipais da Rede Pública Municipal de Ensino de Uberlândia.

\section{A Proposta de Implementação da Gestão Democrática na RME/UDI-2001/2004 - o Programa "Escola Cidadã"}

Dentre os marcos da política educacional na rede municipal de ensino de Uberlândia encontra-se a proposta de implementação da gestão democrática, a partir de 
2001, objeto central dessa pesquisa. A introdução do Programa "Escola Cidadã" na rede municipal de ensino veio ancorada por um discurso em defesa da promoção de um processo de transformação no sentido de "reinventar" as relações entre as pessoas e as escolas, com vistas a implementar a democracia popular, superando as amarras do poder conservador das práticas e do histórico ideário conservador internalizado pela sociedade uberlandense.

Amparada por esse discurso, a Secretaria Municipal de Educação elaborou um documento intitulado Programa Estrutura Político-Pedagógica e Administrativa da Escola Cidadã (PEPAEC), com os objetivos de:

1 - Integrar os educadores da rede, num esforço coletivo, tendo em vista a transformação dos processos de gestão administrativa e pedagógica das escolas públicas municipais, de acordo com os princípios da autonomia relativa e da desburocratização / descentralização dos recursos financeiros destinados às mesmas.

2 - Estimular a participação crítica da comunidade nos destinos da escola, numa perspectiva transformadora de sociedade (SME, 2002-2003, p. 3).

Segundo a justificativa apresentada no documento do PEPAEC,

[...] diante da perspectiva de viver um governo democrático em Uberlândia, afirmávamos no ambiente educacional local que, tomando como ponto de partida uma análise crítica da história desse município, em particular, de sua rede pública de ensino, tornava-se necessário realizar uma profunda avaliação crítica das conseqüências produzidas no imaginário social entre os profissionais da educação, devido a tantos anos de trabalho associado a práticas burocráticas orientadas por um ideário conservador, fortemente enraizado na vida administrativa da Prefeitura Municipal (SME, 2002-2003, p. 4).

Nesse sentido, verifica-se no discurso do programa uma preocupação em romper a cultura autoritária que, além de não possibilitar uma participação democrática, contribuiu como um mecanismo de controle, coerção e submissão e manutenção do status quo da Rede Municipal de Ensino de Uberlândia.

O PEPAEC tomou como parâmetro a experiência da Prefeitura Municipal de Porto Alegre sob a administração do Partido dos Trabalhadores (PT).

No município de Porto Alegre, Azevedo (2000) coloca que a proposta da Escola Cidadã assumiu contornos dispondo-se a redimensionar: as relações de poder, a organização administrativa, os tempos, os espaços e o currículo. A proposta efetivou-se em torno de três eixos: a interdisciplinaridade, a avaliação emancipatória e a educação popular. Em relação à ação do município de Porto Alegre, Azevedo (2000) afirma que a ação da administração municipal configura-se numa política de resistência aos ajustes neoliberais, colocando-se na "contramão das políticas do governo federal". Nesse sentido, contribui para a construção de alternativas políticas e econômicas viáveis e possíveis para um projeto democrático e popular. Azevedo (2000, p. 29) afirma que a Escola Cidadã representa uma alternativa real de construção de uma escola pública com qualidade social, "uma escola do nosso tempo, [...] e formadora de sujeitos emancipados e autônomos, capazes de pavimentar o futuro individual e coletivo". 
Considerando a realidade da RME-UDI, foram elencadas no PEPAEC (2002-2003) três diretrizes principais para que a escola pudesse ser encaminhada para uma prática da democracia:

1) Os dirigentes eleitos pela comunidade devem ter a capacidade de compartilhar e negociar as crenças e valores de sua comunidade;

2) As relações entre as pessoas não devem ter caráter coercitivo e manipulativo, mas sim ocorrerem de forma direta e multilateral, pautadas pelo diálogo e discutibilidade irrestrita (MUÑNZ PALAFOX, 2002, p. 23-32);

3) A cooperação, a ajuda mútua e o trabalho coletivo devem ser os requisitos básicos para todas as relações sociais, pautando-se ainda no princípio da igualdade nas relações de poder entre os sujeitos.

A Secretaria Municipal de Educação, sustentada por esse discurso em prol da democracia e da construção de uma "Escola Cidadã", orientou ações num processo de reestruturação, organizado por várias iniciativas.

Dentre essas ações serão analisadas a realização da eleição direta para diretor e vice-diretor e a consolidação da Carta de Princípios Político-Pedagógicos das Escolas da Rede Pública Municipal de Ensino de Uberlândia, discutida e aprovada nos I e II Congresso Constituinte Escolar que aconteceram nos anos de 2003 e 2004, com maior ênfase nessa última, que, segundo o PEPAEC, teve como diretriz fundamental:

[...] a reinvenção da escola, garantindo, ao máximo, tanto o envolvimento e a participação de todos os membros da comunidade (pais, alunos, professores, e funcionários), bem como a organização de processos de trabalho coletivo que garantam a reflexão e a discutibilidade irrestrita de todos os assuntos relacionados com a vida escolar (SME, 2002-2003, p. $10)$.

\section{A) A Eleição de Diretores}

Dentre as propostas do PEPAEC, a Secretaria Municipal de Educação implementou ações num processo de reestruturação de toda a rede por meio de eventos e ações como a substituição de diretores nomeados por diretores eleitos por meio de uma lista tríplice, que consistia na escolha, pela comunidade escolar, de três profissionais da escola, com a escolha definitiva ficando a cargo do poder executivo. Em seguida, a realização da eleição direta para diretor e vice-diretor no final do ano de 2001. A aprovação da Lei $\mathrm{n}^{\circ} 7832$ de 28 de setembro de 2001 regulamentou as eleições de diretores e vice-diretores dos estabelecimentos municipais de ensino, estabelecendo que a escolha deve ser feita de forma direta, secreta e uninominal, assegurando a participação de todos os segmentos da comunidade escolar. No artigo $4^{\circ}, \S 1^{\circ}$, fica estabelecido que os votos dos trabalhadores da educação terão peso de $50 \%$ e da comunidade de pais e alunos $50 \%$.

O primeiro mandato da direção de Escola Municipal por meio do processo de eleição foi de 2 (dois) anos e os mandatos subseqüentes, de acordo com a Lei, de 3 (três) anos. Os candidatos a diretor e vice-diretor, conforme artigo $6^{\circ}$ da Lei 7832, devem apresentar uma proposta de trabalho em consonância com o projeto político pedagógico, no ato da inscrição. Entretanto, tal artigo não foi contemplado uma vez que a realização da $1^{a}$ eleição se deu ainda no ano de 2001, período em que toda a rede estava iniciando o processo de discussão acerca do Projeto Político Pedagógico. Nesse sentido, os candidatos inscritos apresentaram uma proposta própria, ferindo o que previa a Lei. Esse processo 
evidencia que a realização da $1^{a}$ eleição se deu de forma abrupta e precoce, uma vez que a RME-UDI não se encontrava preparada para um passo político tão importante.

Tal fato provocou a incidência de atritos no interior das escolas, resultando em vários processos administrativos que envolviam os candidatos inscritos e demais membros da comunidade escolar. Por outro lado, esse passo pode ter representado uma ruptura com a cultura da burocracia, com a tutela mandonista e o perverso mecanismo de controle social que representava o ato de nomeação dos diretores escolares. A eleição de diretores, dentre outros mecanismos, representa uma possibilidade de materializar no cotidiano escolar a prática democrática da gestão escolar.

\section{B) A Carta de Princípios da Rede Municipal de Ensino de Uberlândia}

De acordo com o PEPAEC foram elaborados três subprojetos articulados para o alcance das metas e dos objetivos para a implementação da gestão democrática na Rede Municipal de Ensino de Uberlândia:

> Subprojeto 1: Construção da Carta de Princípios da Escola Cidadã.

$>$ Subprojeto 2: Atualização da Proposta Curricular da Rede Municipal de Ensino de Uberlândia.

$>$ Subprojeto 3: Descentralização Administrativa e Financeira da Rede Municipal de Ensino de Uberlândia e Plano de Desenvolvimento da Escola (PADE).

Com a análise da concepção de DEMOCRACIA presente na Carta de Princípios Político-Pedagógicos (CP) da Rede Pública Municipal de Ensino de Uberlândia-MG, volta-se para o "exercício de cidadania na prática da escola cidadã" (SME, 2003). Verificase ainda nessa Carta a presença de pressupostos voltados para a garantia de discussões e ações coletivas, pautadas no "diálogo e na busca constante da participação ativa de pais, alunos, corpo docente e administrativo" (SME, 2003). Nessa direção, fica assegurada nesse documento a criação de "estratégias no sentido de oferecer condições e horários adequados à comunidade escolar, dentro da carga horária do professor, para que este possa participar dos processos de tomadas de decisões, nos quais o diálogo e a busca de consenso devem nortear as discussões" (SME, 2003). Entretanto, a realidade cotidiana das escolas encontrase distante da materialização desse princípio.

Por outro lado, verifica-se que a concepção de DEMOCRACIA presente na CP assenta-se nos pressupostos da democracia representativa e da representação política, processo pelo qual o povo elege um representante delegando seu direito de participar diretamente da política. Nessa concepção, teoricamente, o representante deve procurar atender aos interesses da coletividade. Nesse modelo, a participação direta é colocada em segundo plano. Desse modo, a representação não assegura a representação de agendas e identidades específicas. Além disso, o distanciamento entre representantes e representados é apontado como outra limitação, e a burocratização das práticas e das organizações da representação política impede que os processos decisórios tendam a uma maior informalidade e participação da vontade geral.

Para Santos (2003, p. 75), a solução para o problema da democracia representativa seria a coexistência e complementaridade entre a democracia representativa e a democracia participativa. Embora no texto da CP conste a preocupação com "outras atitudes e métodos democráticos" (SME, 2004), não ficam explícitos quais seriam esses mecanismos e se eles caminhariam na direção apontada por Santos (2003), que defende a conjugação entre a democracia representativa e a democracia participativa, na perspectiva de possibilitar aos 
sujeitos a participação nas decisões, por meio de mecanismos capazes de aperfeiçoar o sistema de representação e o aprimoramento da democracia representativa.

Essa ausência pode contribuir para o reforço da tendência assumida pela democracia representativa, concepção hegemônica da democracia na segunda metade do séc. XX, que consiste em fortalecer a burocratização da participação.

$\mathrm{O}$ pressuposto teórico presente na $\mathrm{CP}$ e nos demais documentos do PEPAEC da SME refere-se à democratização das práticas de gestão administrativa, financeira e pedagógica da escola. Em relação aos princípios de Gestão Democrática, no âmbito teórico, os mesmos implicam uma erradicação das práticas hierarquizadas, autoritárias e burocráticas do sistema educacional. Para isso, Gadotti (2000) alerta que uma gestão democrática da escola exige, em primeiro lugar, uma

[...] mudança de mentalidade de todos os membros da comunidade escolar. Mudança que implica deixar de lado o velho preconceito de que a escola pública é apenas um aparelho burocrático do Estado e não uma conquista da comunidade. A gestão democrática da escola implica que a comunidade, os usuários da escola, sejam os seus dirigentes e gestores e não apenas os seus fiscalizadores ou, menos ainda, os meros receptores dos serviços educacionais. Na gestão democrática pais, mães, alunas, alunos, professores e funcionários assumem sua parte de responsabilidade pelo projeto da escola (GADOTTI, 2000, p. 35).

Dessa forma, o PEPAEC, proposto pela SME-UDI, como já foi dito anteriormente, foi buscar referência na experiência do Município de Porto Alegre que se orientou por uma concepção de educação progressista-libertadora. Para Azevedo (2001), essa experiência configura-se numa política de resistência aos ajustes neoliberais e, como tal, coloca-se na contramão das políticas do governo federal. Ao mesmo tempo constrói alternativas políticas e econômicas viáveis e possíveis para um projeto democrático e popular. Ao ir de encontro às práticas neoliberais

[...] a Escola cidadã contrapõe-se à escola de mercado, à "mercoescola", cujos princípios baseiam-se no paradigma neoliberal. A "mercoescola" caracteriza-se pela submissão a valores de mercado, com a preocupação única de formar consumidores e clientes, tornar a educação uma mercadoria submetida à lógica empresarial, naturalizando o individualismo, a competição, a indiferença e, conseqüentemente, a exclusão (AZEVEDO, 2001, p. 147-148).

A proposta da Escola Cidadã opõe-se à ideologia neoliberal que se fundamenta na maximização da liberdade individual e na proteção do mercado contra o Estado. Com isso, o papel do Estado na sociedade passa por um processo de redefinição conduzido pela ideologia neoliberal que sustenta que o mercado deve ser deixado livre para estabelecer suas próprias regras.

Dentre os conceitos básicos do neoliberalismo, o indivíduo constitui um átomo social do sistema econômico. Nessa concepção, o indivíduo é enfocado como o resultado da combinação dos genes herdados com a ação voluntária. Seguindo esse raciocínio, o êxito e o fracasso individual são consequiências das condições do próprio indivíduo. Em decorrência dessa tese, para o modelo neoliberal, as causas das desigualdades são associadas ao âmbito do indivíduo e atribuídas como uma questão de "sorte" e não como reflexos das condições estruturais da sociedade capitalista. 
O neoliberalismo, comprometido com o processo de reestruturação do capitalismo, concebe o Estado como um obstáculo à sua expansão transnacional, na medida em que pode determinar políticas restritivas e protecionistas ao mercado interno. Em oposição a esse modelo protecionista, a configuração do Estado em consonância com a era da globalização da economia é o "Estado Mínimo".

Essa configuração do Estado fiel ao modelo neoliberal combate qualquer ação estatal, em especial no âmbito das políticas sociais. Para a ideologia neoliberal, as políticas sociais do Estado elevam seus gastos e como resultado provocam um aumento da pressão fiscal sobre os setores detentores do capital, que não são diretamente beneficiados dessas políticas.

Em oposição, a Escola Cidadã propõe a transformação do caráter privado do Estado para um Estado público, em que a participação popular induz as ações do Estado, ao atuar na construção e na fiscalização da aplicação das políticas públicas (AZEVEDO, 2001, p. 145).

Considerando esses embates, a proposta Escola Cidadã configura-se numa política de resistência aos ajustes neoliberais e, como tal, coloca-se na contramão das políticas guiadas pela lógica do capitalismo. Além disso, propõe alternativas políticas e econômicas viáveis e possíveis para um projeto democrático e popular, considerando as contradições entre a lógica neoliberal e a lógica da democracia que sustenta a proposta Escola Cidadã.

\section{Os limites e as possibilidades da democratização da Escola Pública}

A experiência local da RME-UDI pode representar uma questão contraditória e antagônica. Se, por um lado, podem reproduzir o autoritarismo pela via da fragmentação das práticas e serviços de interesse público, por outro lado, tal experiência contempla vontades de sujeitos sociais com condições históricas locais e pode constituir-se numa esfera pública democrática. Assim, a proposta de implementação de gestão democrática na Rede municipal de Ensino de Uberlândia (RME/UDI), no período de 2001 a 2004, foi analisada considerando a gestão do prefeito Zaire Rezende, que em seu Programa de Governo apresentou a Escola Cidadã como proposta de gestão do ensino.

Para a análise dessa experiência, fez-se necessário resgatar a real conjuntura política do município de Uberlândia. Verificou-se que ela é marcada pela predominância de elementos de uma cultura política conservadora que dificulta a consolidação de novas propostas de gestão que possam ampliar o escopo das decisões. As experiências como a Democracia Participativa da década de 1980 e o Orçamento Participativo na gestão de 2001-2004, ambas do prefeito Zaire Rezende, evidenciaram que a tradição política em Uberlândia reforça a anulação da participação popular no cenário do poder de decisão. Esse contexto, marcado por muitas tensões e dificuldades, atrofiou a tentativa de implantação de propostas como do Orçamento Participativo, que assinalava uma divisão do poder que sempre se encontrou centralizado nas mãos das elites dirigentes do município.

Nesse cenário, encontram-se os marcos da proposta de implementação da gestão democrática na rede municipal de ensino de Uberlândia, a partir de 2001. Verificou-se que a introdução do Programa "Escola Cidadã" na rede municipal de ensino sustentou-se por um discurso em defesa da promoção de um processo de transformação no sentido de "reinventar" as relações entre as pessoas e as escolas, com vistas a implementar a democracia popular, superando as amarras do poder conservador das práticas e do histórico ideário conservador internalizado pela sociedade uberlandense. No discurso presente no programa, presencia-se uma preocupação em romper a cultura autoritária que não 
possibilita uma participação democrática e consolida mecanismos de controle, coerção e submissão.

A Secretaria Municipal de Educação, por meio da PEPAEC, orientou diversas ações, buscando uma concepção de educação progressista-libertadora que se configura numa política de resistência aos ajustes neoliberais, na contramão das políticas do governo federal.

Um aspecto a destacar dentre as diversas ações implementadas no período de 20012004 refere-se à modalidade de escolha para diretores das escolas municipais. Na RMEUDI, somente a partir de 2001 a modalidade de escolha para diretor passa a ser mediante eleição direta que prevê a manifestação da vontade das pessoas envolvidas na vida da unidade escolar por meio de voto direto. Pode-se inferir que esse "retardamento" em relação à implementação da eleição de diretores na RME-UDI pode ser atribuído pelo caráter patrimonialista e clientelista que marca a conjuntura política no município de Uberlândia. A conjuntura política do município de Uberlândia é marcada pela predominância de elementos de uma cultura política conservadora que confundem o público com o privado, em que se destaca o clientelismo, o voto trocado por um favor ou à custa de promessas e não de compromissos com a maioria da população, configurando extremas práticas patrimoniais. Esse caráter conservador da política local explica o fato do provimento por eleição passar a ser realidade na RME-UDI somente em 2001, uma vez que a eleição de diretores já faz parte da realidade de vários municípios brasileiros.

No entanto, verifica-se também que a gestão democrática na escola não está garantida somente com a eleição de diretores. Torna-se necessária a implementação de outras ações no sentido de superar os entraves cristalizados no cotidiano escolar e na conjuntura política da sociedade. A presença da idéia de que o sistema é democrático por ter simplesmente estabelecido a eleição para o diretor da escola limita a compreensão da dimensão que envolve a gestão democrática. Embora a eleição de diretores seja um dos mecanismos essenciais no processo de democratização da escola e dos sistemas de ensino, ela não é capaz, por si só, de alterar a estrutura centralizada e os comportamentos antidemocráticos que prevalecem na trajetória da política educacional. Ou seja, mesmo com a implementação de eleição de diretor, a verdadeira prática democrática pode estar distante do cotidiano da comunidade educacional.

Diante disso, pode-se depreender que a implementação efetiva da gestão democrática na escola implica um redirecionamento das políticas educacionais. Apenas mudar o processo de preenchimento da vaga do cargo de diretor escolar pela via da eleição direta não basta, quando se tem como meta a efetivação de uma gestão democrática.

A questão cultural atrelada a um ideário conservador não permite uma assimilação plena da concepção de democracia e pode fazer com que a noção de "participação" sofra um processo de ressignificação. Nesse processo, o conceito de participação pode assumir uma dimensão privatista e individualista, capaz de substituir e redefinir o significado coletivo da participação social.

Considerando esse cenário, os resultados desse estudo evidenciaram que a gestão democrática aparece na racionalidade dos sujeitos como algo distante, um postulado que se encontra num futuro remoto. A realidade da gestão democrática apresenta-se como um processo novo que precisa ser implementado tanto na dimensão da escola como na dimensão do sistema escolar. A análise dos depoimentos revelou que a centralização das decisões representa um entrave para a consolidação da gestão democrática, cristalizando um caráter descendente das decisões e das ações por parte dos órgãos centrais de educação, não considerando a pluralidade das escolas. 
Esse caráter descendente e centralizador das políticas permeia toda a estrutura do sistema escolar brasileiro, fato que precisa ser superado para a efetivação de uma gestão democrática. Nesse sentido, apesar da aprovação da Carta de Princípios da RME-UDI e dos princípios de gestão democrática, as entrevistas realizadas sinalizaram uma não materialização dos mesmos na prática das escolas. Evidencia-se a presença da grande mazela na educação, que faz com que os projetos sejam sempre engavetados, provocando uma desmotivação nos profissionais da educação e uma apatia no sentido de propor mudanças.

O Programa Escola Cidadã apresenta teoricamente uma preocupação em romper a cultura autoritária que, além de não possibilitar uma participação democrática, contribuiu como um mecanismo de controle e submissão da Rede Municipal de Ensino de Uberlândia. Entretanto, pode-se inferir que a implementação da gestão democrática na RME-UDI não está garantida somente com a elaboração de documentos e projetos, tendo em vista o jogo de forças envolvidas e a suplantação dos entraves cristalizados no cotidiano escolar, tais como: a cultura autoritária sedimentada ao longo da história educacional; espaço reduzido de participação da comunidade escolar nos processos decisórios; compreensão equivocada por parte dos governantes de que apenas por um ato legal, o processo de gestão democrática estaria definitivamente implantado. A gestão democrática não pode ser reduzida a eventos esporádicos e isolados. Ela deve fazer parte de um amplo processo que envolve procedimentos, instrumentos e mecanismos de ação.

Diante das dificuldades para a implementação da proposta de gestão democrática na RME-UDI, a descontinuidade das políticas educacionais e da gestão do sistema aparece como categoria central. Essa descontinuidade interfere na concretização de mecanismos de gestão democrática. As resistências e dificuldades apontadas para a concretização de mecanismos de gestão democrática nos depoimentos vinculam-se à concepção de educação que cada governo apresenta e à forma de conduzir a gestão da educação. Essa descontinuidade e a ausência de um projeto e de uma política educacional autônoma e consistente fazem da educação do município um cenário de episódios isolados e incoerentes com o propósito de uma gestão democrática. Verificou-se que essa descontinuidade pode ocorrer devido às divergências políticas e ideológicas dos membros que estão à frente da SME.

Com isso, a existência de intervenções político-partidárias e a relação entre o poder político e a gestão da educação representam também um dos entraves à implementação de propostas de gestão democrática. Tendo em vista esse cenário de descontinuidade, a materialização de propostas progressistas que reconhecem a participação popular no processo de tomada de decisão, que assegurem uma gestão democrática, está distante da prática cotidiana das escolas e da SME.

Além disso, vale ressaltar que uma gestão democrática para ser efetivada em sua plenitude implica ser pensada no universo do sistema de ensino. Uma gestão democrática não se limita aos muros da escola. Não depende somente da escola a superação da estrutura hierárquica na qual os sistemas de ensino se encontram cristalizados.

A tradição autoritária fortemente arraigada em toda sociedade patrimonialista e clientelista conduz o comportamento dos indivíduos que optam em não participar do processo de tomada de decisões. A cultura autoritária que sustenta a sociedade associada ao processo de tomada de decisão por representatividade contribui e reforça o comportamento apático e acomodado dos sujeitos. Nesse sentido, a ausência de uma tradição democrática, associada à presença de um autoritarismo cristalizado, dificulta a implantação de mecanismos participativos de gestão. 


\section{Considerações finais}

Os objetivos previstos no Programa Escola Cidadã não foram implementados em sua totalidade e, percebe-se que a prática de uma gestão democrática ainda se encontra distante da realidade das escolas. A inviabilidade dos objetivos do Programa Escola Cidadã refere-se à falta de uma política educacional consistente e à presença de uma política partidária que não submeta a concepção de educação a interesses político-partidários.

Por fim, ainda existem concepções autoritárias e práticas centralizadoras arraigadas na estrutura e organização do sistema escolar, sedimentando um campo pouco fértil para a consolidação de mecanismos e políticas educacionais voltados para a gestão democrática. Embora a Proposta Escola Cidadã teoricamente tenha tentado implementar uma gestão democrática, na prática ela não conseguiu romper plenamente com os entraves cristalizados. A estrutura das escolas e do sistema de ensino ainda se encontra aquém de uma temática da democratização da escola pública. Nesse contexto, são escassos os mecanismos reais de participação e de exercício de democracia que a escola vem implementando de modo a garantir o envolvimento de todos no processo de decisão e, conseqüientemente, no aperfeiçoamento do processo democrático.

A gestão democrática faz parte de um processo amplo que envolve mecanismos, procedimentos e instrumentos de ação que ultrapassam o interior das unidades escolares, atingindo níveis da política educacional e do planejamento educacional. Nesse sentido, pode-se verificar que o Programa não foi capaz de efetivar a gestão democrática, pois não conseguiu romper com as estruturas centralizadoras que perpassam por toda a estrutura da escola e do sistema público de ensino brasileiro.

Destaca-se, por fim, que as inferências apontadas nesta pesquisa permitem vislumbrar os limites para a implementação plena da gestão democrática na escola pública, que apesar de todos os fatores e mecanismos de gestão democrática do ensino público convergem para a democracia e a participação dos sujeitos nos rumos da escola. Democracia e participação ainda têm desempenhado um papel periférico, diante do cenário macro de autoritarismo e centralização em que estão inseridos os sistemas de ensino. Por outro lado, existe a necessidade de maior compreensão da dinâmica das relações entre a escola e os órgãos superiores da administração e da descontinuidade das políticas educacionais e da gestão da educação. Assim, existe uma carência de novas pesquisas, com vistas a vislumbrar as possibilidades de uma escola democrática com uma proposta participativa e de uma política educacional autônoma e consistente. Uma política educacional capaz de romper a lacuna existente entre a intenção e o gesto, o legal e o real, o discurso e a prática cotidiana.

\section{Referências}

AZEVEDO, José Clóvis de. Escola cidadã: desafios, diálogos e travessias. Petrópolis: Vozes, 2000.

Escola Cidadã: a experiência de Porto alegre. In: OLIVEIRA, Dalila Andrade e DUARTE, Marisa R. T. (Org). Política e Trabalho na Escola: administração dos Sistemas Públicos de Educação Básica. Belo Horizonte: Autêntica, 2001 p. 143-155.

GADOTTI, Moacir. Perspectivas atuais da educação. Porto Alegre: Armed, 2000. 
MUÑOZ PALAFOX, G. Educação Popular: considerações políticas e metodológicas. Uberlândia: Revista de Educação Popular. Universidade Federal de Uberlândia, 1(1): 23$32,2002$.

PREFEITURA DE UBERLÂNDIA. $13^{a}$ edição do Banco de Dados Integrados do Município de Uberlândia. Uberlândia: Secretaria Municipal de Planejamento e Desenvolvimento Urbano, 2005.

PROGRAMA DE GOVERNO - Coligação Agora é Zaire, 2000.

SECRETARIA MUNICIPAL DE EDUCAÇÃO. A caminho da construção de uma Escola Cidadã-Referenciais Teóricos. Uberlândia, 2002. (Apostila).

- Carta de Princípios das Escolas da rede Pública Municipal de ensino de Uberlândia. Uberlândia, 2003. (Apostila).

Elaboração da Carta de Princípios da Escola Cidadã. Uberlândia, [s.d.].

Histórico da Construção da Carta de Princípios da Rede Municipal de Ensino de Uberlândia, [s.d.]. (Apostila).

. Programa Estrutura Político-Pedagógica e Administrativa da Escola Cidadã. Uberlândia, 2002-2003.

UBERLÂNDIA (MG). Lei Orgânica do Município de Uberlândia Minas Gerais. Uberlândia, MG: Câmara Municipal de Uberlândia, 1992.

Lei Municipal $n^{\circ} 7832$ de setembro de 2001. Uberlândia, MG: Câmara Municipal de Uberlândia, 2001.

\footnotetext{
${ }^{\text {i }}$ Este artigo é baseado na dissertação de mestrado intitulada 'A Proposta de Democratização da Educação na Rede Municipal de Ensino de Uberlândia-Mg (2001-2004): Limites e Possibilidades da Democracia na Escola Pública', defendida na Universidade Federal de Uberlândia em 2006 no Programa de Pós-graduação em Educação.

${ }^{\text {ii }}$ Mestre em Educação pela Universidade Federal de Uberlândia, na Linha de Pesquisa Políticas e Gestão em Educação. Professora do curso de Pedagogia da Universidade Federal de Uberlândia - Campus do Pontal. Email: vilmasouza@pontal.ufu.br.

iii Paulo Freire definiu a Escola Cidadã como "aquela que se assume como um centro de direitos, como um centro de deveres. O que caracteriza a escola cidadã é uma formação para a cidadania”. (cf. Padilha, 2001).

iv Seminário intitulado "Projeto Político Pedagógico: um bicho de sete cabeças?" que envolveu todas as escolas da Rede Municipal de Ensino de Uberlândia com o objetivo de discutir os pressupostos políticopedagógicos da "Escola Cidadã".

${ }^{v}$ Implantada com a Lei Municipal no 7832 de setembro de 2001.
}

Artigo recebido em: 10/10/09

Aprovado para publicação em: 05/03/2010 